\title{
Registration of synchronous geomagnetic pulsations and proton aurora during the substorm on March 1, 2017
}

\author{
Ilya Varlamov $^{1,2, *}$, Stanislav Parnikov², Igor Ievenko², Dmitry Baishev², and Kazuo \\ Shiokawa ${ }^{3}$ \\ ${ }^{1}$ M.K. Ammosov North-Eastern Federal University, Yakutsk, Russia \\ ${ }^{2}$ Yu.G. Shafer Institute of Cosmophysical Research and Aeronomy SB RAS, Yakut Scientific Centre \\ SB RAS, Yakutsk, Russia \\ ${ }^{3}$ Institute for Space-Earth Environmental Research, Nagoya University, Japan
}

\begin{abstract}
Data of synchronous geomagnetic pulsations and proton aurora registrations were analyzed during the substorm on March 1, 2017 at Zhigansk ( $\mathrm{L}=4.5$, induction magnetometer), Maimaga $(\mathrm{L}=4$, all-sky imager and Yakutsk $(\mathrm{L}=3.3$, induction magnetometer) stations, simultaneously with satellite measurement of EMIC waves. Ground-based registration of proton aurora is very difficult due to the fact that their intensity is much lower than the aurora intensity caused by precipitations of electrons, but in the event of substorm activity at the zenith of Maimaga station, a narrow (1 degree in latitude) proton arc was observed. Irregular pulsations of the diminishing periods (IPDPs) in the range of Pcl geomagnetic pulsations associated with the injection of energetic protons were recorded simultaneously at Zhigansk and Yakutsk stations. This is the first report when STEVE (Strong Thermal Emission Velocity Enhancement) was observed in the course of a substorm with the onset at 12:45 UT after the decay of Pc1-associated proton arc. It is shown that the proton arc and geomagnetic pulsations are a consequence of ion-cyclotron instability in the area of the outer plasmasphere overlapping by energetic protons.
\end{abstract}

\section{Introduction}

In the area of overlapping of the outer plasmasphere (plasmapause) by ring current ions, many processes arise, the results of which, in particular, are electromagnetic ion cyclotron (EMIC) waves, mid-latitude stable auroral red (SAR) arcs and proton auroras, equatorward of the auroral oval. EMIC waves are generated as a result of ionic instabilities arising from mixing of hot and cold plasma. SAR arcs are the result of heating the outer plasmasphere by energetic ring current ions. The flux of superthermal electrons arising due to the Coulomb interaction, as a result of thermal conductivity, along the field lines, flows downward and causes a weak, monochromatic glow at the heights of the F2 layer of the ionosphere [1]. Proton arcs are a consequence of the generation of EMIC waves that scatter protons at pitch

*Corresponding author: varlamovi@mail.ru 
angles into a loss cone [2]. During precipitation, protons undergo a recharge, as a result of which excited hydrogen atoms are formed. In the visible part of the spectrum, the $\mathrm{H} \alpha$ and $\mathrm{H} \beta$ lines are emitted by which the precipitation of protons from the Earth is identified. EMIC waves manifest themselves in the form of variations in the components of the magnetic field in the region of generation and geomagnetic pulsations of the Pc1 range on the Earth.

In this work, the results of the analysis of data of synchronous registration of geomagnetic pulsations at Zhigansk and Yakutsk, as well as optical registration of proton auroras and SAR arc at the Maimaga subauroral station during the event on March 1, 2017, are presented.

\section{Equipment and methods for analysis of observation data}

Registration of geomagnetic pulsations was carried out at the Oybenkel radiophysical polygon $\left(56^{\circ} \mathrm{N}, 199^{\circ} \mathrm{E}\right.$ geom., $\left.\mathrm{L}=3.3\right)$ near Yakutsk and the complex geophysical station Zhigansk $\left(62^{\circ} \mathrm{N}, 196^{\circ} \mathrm{E}\right.$ geom., $\left.\mathrm{L}=4.5\right)$.

Measurements of magnetic field variations and natural electrical potentials at the Oybenkel polygon are carried out using a 24-bit geophysical electromagnetic measuring system METRONIX ADU-07e. The electric and magnetic field sensors are connected directly to the ADU-07 (Analog / Digital Signal Conditioning Unit), which is the main unit of the system. The sampling rate is $16 \mathrm{~Hz}$.

Several different types of induction magnetometer sensors are used in the PWING project [3]. One is the preexisting sensors before the PWING project, i.e., those made by Tierra Technica (ULC-150) for Zhigansk. The sampling rate is $64 \mathrm{~Hz}$. Geomagnetically northward (H-) component and eastward (D-) component are recorded in the first and second channels, respectively, while the riometer output is recorded at the third channel. The 1 pulse-persecond (PPS) signal generated by a GPS receiver is recorded in the fourth channel as a time standard.

Optical observations were carried out at the Maimaga station of the SHICRA SB RAS $\left(58^{\circ} \mathrm{N}, 200^{\circ} \mathrm{E}\right.$ geom., $\left.\mathrm{L}=4\right)$. The luminosity was recorded using a «Keo Sentry» all-sky imager. The camera has a PI Acton ProEM 1024B CCD device and is equipped with six cavity interference filters with a half-width transmission of $2 \mathrm{~nm}$. The filters are centered at wavelengths 557.7 and 630.0 [OI], $470.9(\mathrm{~N} 2+), 486.1(\mathrm{H} \beta), 620.0$ (continuum), 480.0 (continuum) $\mathrm{nm}$.

The time-frequency spectral analysis of the geomagnetic pulsation data was carried out using the multistage Thomson method (MTM).

All-sky imager data are presented in this work in the form of all sky images and keograms projected onto the Earth's surface for luminosity heights of $110 \mathrm{~km}$ for emissions of 486.1 and $557.7 \mathrm{~nm}$ and $250 \mathrm{~km}$ for emissions of $630.0 \mathrm{~nm}$. The signal intensity is given in kilorayleighs.

Due to the irregularity of the proton luminosity of arc along latitude, the keograms were plotted along a relatively narrow longitudinal sector, along the 198th geomagnetic meridian, where the luminosity of arc was most often observed in the $486.1 \mathrm{~nm}$ emission. The keograms are constructed without taking into account the Van Rijn effect.

Keograms for emissions 557.7 and 630.0 were obtained with the subtraction of the continuum in the vicinity of $620.0 \mathrm{~nm}$, for the emission of 486.1, the subtraction of the intensity of the continuum in the region of $480.0 \mathrm{~nm}$ was made. 


\section{Results}

The event under consideration occurs in the MLT pre-midnight sector and is not stationary, proceeding against the background of weak but regular magnetospheric activations (see Fig. 1). According to data from mid-latitude stations (not shown here, see Fig. 2 in [4]), the next substorm activation occurred at $\sim 12: 45$ UT on the Magadan meridian.

The proton arc arising in the vicinity of the zenith of the optical observation station had an uneven glow along the latitude. Separate maxima moved along the arc, in an easterly direction.

The speed of the eastern motion of the maxima observed before 13:03 UT was $\sim 600 \mathrm{~m} /$ s. After 13:03 UT, the irregularities stopped reaching the station meridian and were observed on the western horizon. Example of irregularity in the luminosity of an arc is shown on the left part of Figure 2.
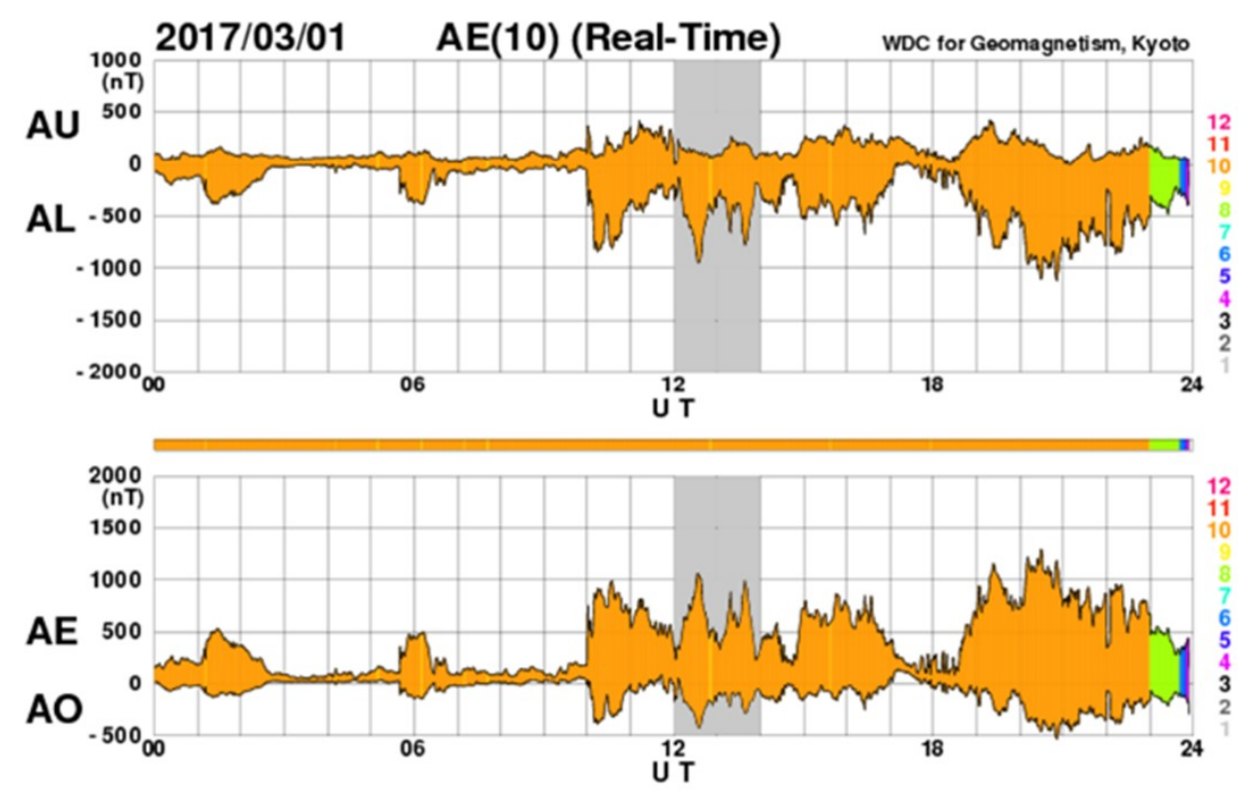

[Created at 2017-03-02 00:00UT]

Fig. 1. Auroral indices on March 1, 2017 according to the Kyoto World Data Center for Geomagnetism.

The keograms shown in Figure 2 show the latitudinal dynamics of proton auroras and SAR arc. From the beginning of the considered period, a weak SAR arc was recorded $\sim 200$ $\mathrm{km}$ north of the station zenith. As the activity intensified, the red arc moved in the equatorial direction along the polar boundary of the diffuse aurora and crossed the zenith of the observation station at $\sim 12: 40 \mathrm{UT}$.

With the appearance of a proton arc at the same latitudes as the SAR-arc (SAR arc), the luminosity in the $630.0 \mathrm{~nm}$ emission intensified. Both structures moved synchronously along the latitude of the observation station. The total luminosity intensity in the $630.0 \mathrm{~nm}$ emission caused by the red and proton arcs reached $\sim 150$ Rayleigh. After the attenuation of the proton arc, the red arc continued to exist in the vicinity of the station zenith until 14:13 UT.

Also, among the features of the subauroral luminosity in the period under consideration, it can be noted that immediately after the proton arc decay, more polar than the SAR arc from 
13: 23UT, STEVE began to form, accompanied by a picket fence (PF) (see the keograms in the 630.0 and $557.7 \mathrm{~nm}$ Fig. 2) [5].

In the $\mathrm{H} \beta(486.1 \mathrm{~nm})$ emission from $\sim 12: 20 \mathrm{UT}$ on the northern horizon, a wide band of proton aurora appeared (marked in the frames as a proton band), moving in the equatorial direction. At $\sim 12: 55 \mathrm{UT}$, for all emissions presented on the keograms, a sharp increase in the glow was recorded throughout the sky. After a brief flare, the equatorial boundary of the wide proton band began to recede.

From 12:35 UT, south of this band, at a distance of $\sim 100 \mathrm{~km}$ from its near boundary, in the vicinity of the station zenith, along the existing SAR arc, a narrow proton arc appeared with an uneven distribution of the luminosity intensity along it. From the very beginning of the formation, the "non-uniform" arc began to move equatorially and by the time of the flare across the sky at $\sim 12: 55 \mathrm{UT}$, had already crossed the zenith of the station. During this initial period of time, the proton arc was most dynamic in the equatorial direction, its velocity reached values in $\sim 150 \mathrm{~m} / \mathrm{s}$.

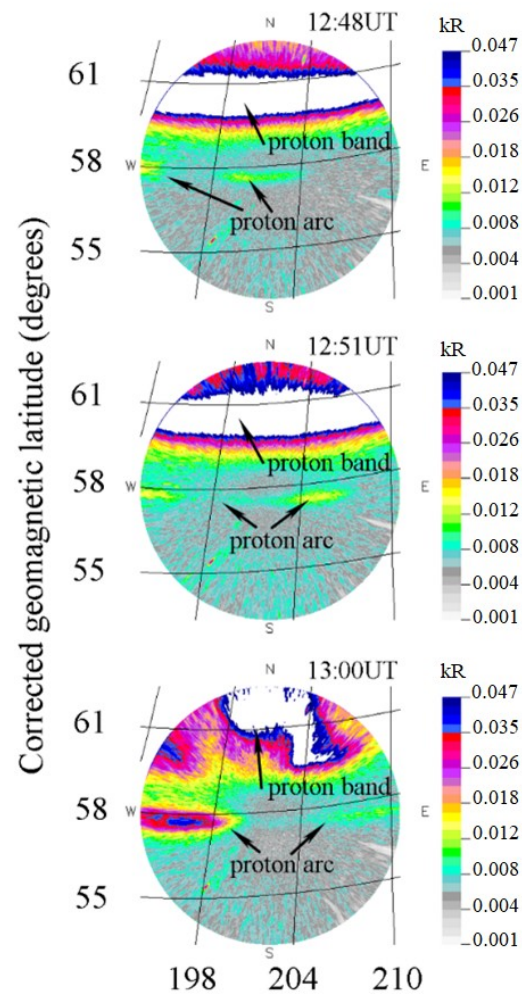

Corrected geom. long. (deg.)
March 1, 2017

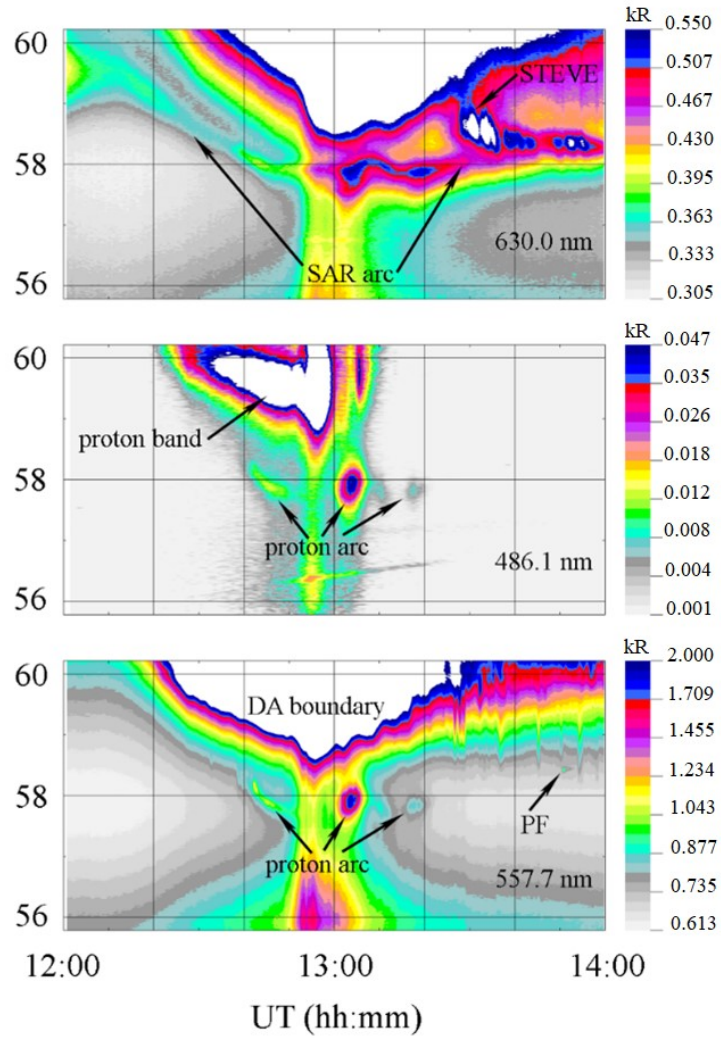

Fig. 2. Dynamics of subauroral luminosity at Maimaga station during observations on March 1, 2017. On the left side of the figure are images of all sky in emission of $486.1 \mathrm{~nm}$ for three points in time indicated in the images. The right side of the figure shows the latitudinal dynamics of the luminosity in the 630.0, 486.1, and $557.7 \mathrm{~nm}$ emissions in the form of keograms. All sky images and keograms projected onto the Earth's surface for luminosity heights of $110 \mathrm{~km}$ for emissions of 486.1 and 557.7 $\mathrm{nm}$ and $250 \mathrm{~km}$ for emissions of $630.0 \mathrm{~nm}$. The signal intensity is given in kilorayleighs. 
Further, the position of the arc has stabilized. The proton arc reached its culmination (maximum width and brightness) at 13: 03UT. At this moment, the arc width reached $\sim 100$ $\mathrm{km}$, and the intensity in the $\mathrm{H} \beta$ emission was $\sim 40$ Rayleigh. By 13: 22UT, the proton arc, which existed at the latitudes of red, fades out.
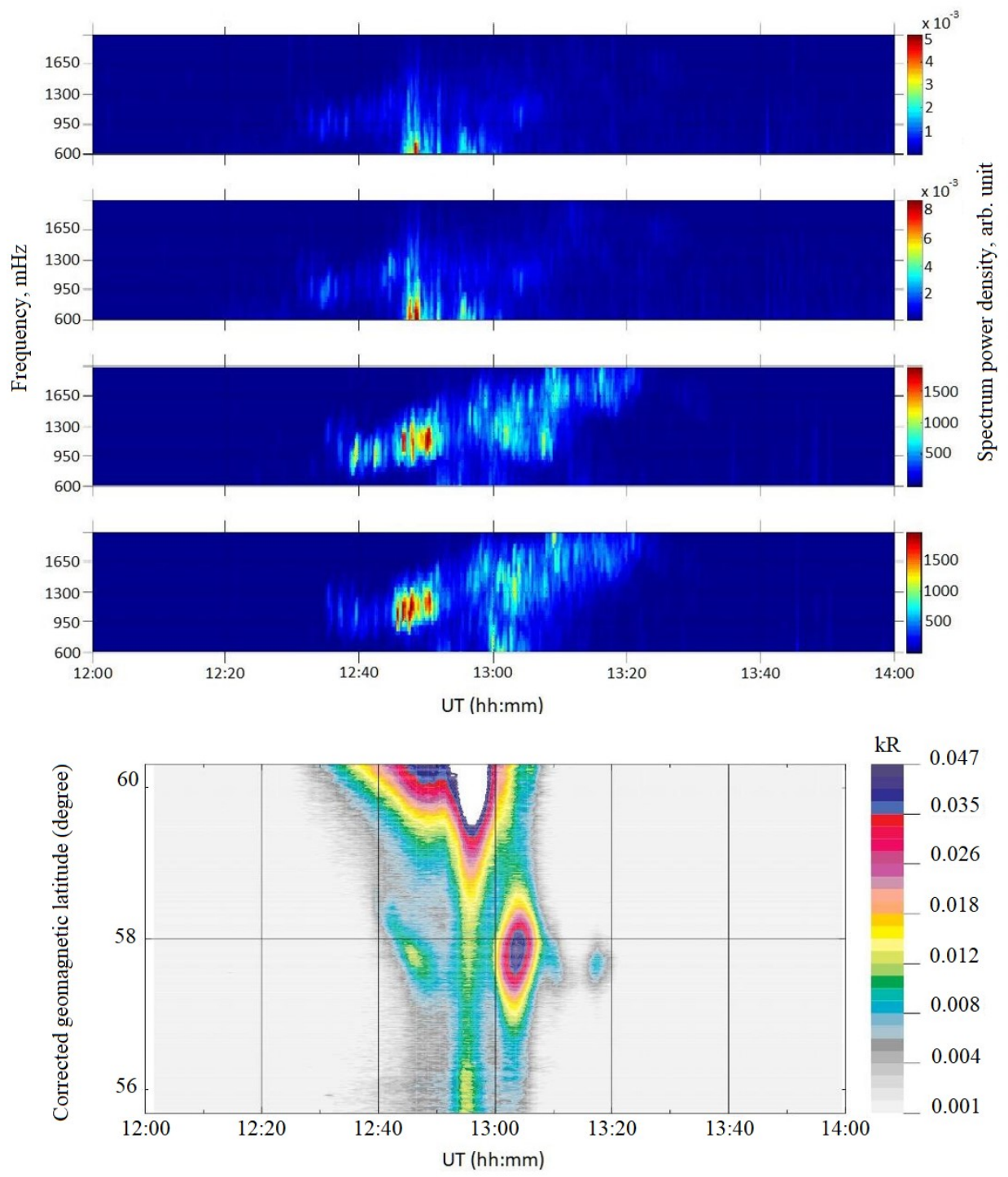

Fig. 3. From top to bottom, spectrograms of the $\mathrm{H}$ and $\mathrm{D}$ components at Zhigansk and Yakutsk stations, and the latitudinal keogram of the luminosity in the $486.1 \mathrm{~nm}$ emission at $110 \mathrm{~km}$ during observations on March 1, 2017 at 12:00-14:00 UT. The signal intensity is given in kilorayleighs.

In the $557.7 \mathrm{~nm}$ emission, the dynamics of the proton arc is expectedly similar to the dynamics in the $486.1 \mathrm{~nm}$ emission. The intensity of the proton arc in the green emission was much higher than in the $\mathrm{H} \beta$ emission and at the time of the culmination at 13:03 UT reached $\sim 1000$ Rayleighs. Also, in the $557.7 \mathrm{~nm}$ emission, it can be seen that by the time of the flare throughout the sky at $\sim 12: 55 \mathrm{UT}$, the diffuse aurora boundary reached the zenith of the Maimaga station. 
The spectrograms of the $\mathrm{H}$ and $\mathrm{D}$ components at Zhigansk and Yakutsk stations in Fig. 3 showed that in the interval 12:30-12:55 UT, geomagnetic pulsations Pc1 were recorded in the frequency range $0.9-1.3 \mathrm{~Hz}$. Note that at Zhigansk station, Pc1 pulsations were recorded in time earlier than pulsations at Yakutsk station, the behavior and intensity of which coincided with the registration and dynamics of narrow proton arcs at the zenith of Maimaga station (starting from 12:35 UT). The fact of early registration of Pc1 pulsation at Zhigansk station indicates that the region of generation of narrow proton arcs was localized closer to the longitude of Zhigansk station than at the longitude of Yakutsk station, which is confirmed by direct optical observations of proton arcs at Maimaga station.

Figure 3 also clearly illustrates that the displacement of narrow proton arcs to low latitudes led to a noticeable increase in both the frequency and intensity of Pc1 pulsations at Yakutsk station, which, however, coincided in time with substorm activation, namely, the excitation of irregular geomagnetic pulsations at station Zhigansk.

A sharp increase in the luminosity over the entire sky at $\sim 12: 55$ UT led to the attenuation of the Pc1 pulsations in the frequency range $0.9-1.3 \mathrm{~Hz}$. Further, in the interval 12:58-13:10 UT at Zhigansk and Yakutsk stations, IPDP was recorded with an increase in frequency from 1 to $2 \mathrm{~Hz}$ in 12 minutes, possibly due to substorm activation at $~ 12: 45 \mathrm{UT}$ on the Magadan meridian. The IPDP intensity at Yakutsk station is more noticeable than at Zhigansk station, and it is associated with the proton arc recorded at the zenith of Maimaga station in the interval 12:58-13:10 UT, although there was no obvious radial drift in the arc dynamics.

In the interval 13:10-13:22 UT, only at Yakustk station, Pc1 pulsations were recorded in the frequency range 1.6-2 Hz, closely related to the observation of the proton arc at Maimaga station.

\section{Discussion and summary}

Data of synchronous geomagnetic pulsations at Zhigansk $(\mathrm{L}=4.5)$ and Yakutsk $(\mathrm{L}=3.3)$ and isolated proton arc registrations at Maimaga $(\mathrm{L}=4)$ showed one-to-one correspondence between magnetic and optical phenomena. Geomagnetic pulsations at Yakutsk in the interval of 12:35-12:55 UT coincided with isolated proton arc registrations at Maimaga and association of frequency growth of pulsations with equatorward motion of proton arc is clearly seen.

Irregular pulsations of the diminishing periods (IPDPs) in the range of 1-2 $\mathrm{Hz}$ in the interval of 12:58-13:10 UT were recorded simultaneously at Zhigansk and Yakutsk accompanying with intense isolated proton arc registrations at Maimaga. As shown by Baishev et al. [6] these magnetic and optical phenomena were associated with the injection of energetic protons after second substorm activation with onset at 12:45 UT.

New finding is optical observation of STEVE at Maimaga starting from 13:23 UT after the decay of Pc1-associated proton arc registered in the interval 13:10-13:22 UT. Groundbased synchronous optical and geomagnetic observations showed complex physical phenomena in the course of a substorm.

Two-dimensional images of the isolated proton arc showed that its narrow (1 degree) latitudinal widths and limited longitudinal lengths are in agreement with measurements of isolated auroral arcs at Athabasca [7].

Thus it is shown that the proton arc and geomagnetic pulsations are a consequence of ioncyclotron instability in the area of the outer plasmasphere overlapping by energetic protons.

A sharp increase in the luminosity over the entire sky for all emissions at $\sim 12: 55$ UT and a short-term attenuation of geomagnetic pulsations Pc1, and STEVE occurrence starting from 13:23 UT require further studies using additional ground-based and satellite measurements.

This work was carried out with the financial support of the RFBR grant No. 21-55-500. 


\section{References}

1. K. Cole, J. Geophys. Res., 70 (1965)

2. T. A. Yahnina, A. G. Yahnin, J. Kangas, J. Manninen, D. S. Evans, A. G. Demekhov, V. Y. Trakhtengerts, M. F. Thomsen, G. D. Reeves, and B. B. Gvozdevsky, Ann. Geophys., 21 (2003)

3. K. Shiokawa, Y. Katoh, Y. Hamaguchi et al, Earth Planets Space, 69, 160 (2017)

4. S.G. Parnikov, I.B. Ievenko, D.G. Baishev, I.I. Koltovskoy Proton aurora observation as a result of ion cyclotron instability, in Proceedings of the SPIE 11560, 26th International Symposium on Atmospheric and Ocean Optics: Atmospheric Physics, 12 November 2020, Moscow, Russia (2020)

5. E.A. MacDonald, E. Donovan, Y. Nishimura, et al, Sci. Adv., 4 (2018)

6. D.G. Baishev, E.S. Barkova, S.I. Solovyev, K. Yumoto, A.G. Yahnin, IJGA, 2, 2 (2000)

7. K. Sakaguchi, K. Shiokawa, Y. Miyoshi, Y. Otsuka, T. Ogawa, K. Asamura, M. Connors, J. Geophys. Res., 113 (2008) 